\title{
Promoting long-term forest landscape resilience in the Lake Tahoe basin
}

Eric S. Abelson ${ }^{* a b}$, Keith M. Reynolds ${ }^{c}$, Angela M. White ${ }^{a}$, Jonathan W. Long ${ }^{a}$, Charles Maxwell $^{\mathrm{d}}$, Patricia N. Manley ${ }^{\mathrm{a}}$

${ }^{a}$ United States Department of Agriculture, Forest Service, Pacific Southwest Research Station, Davis, CA 95618, USA.

${ }^{b}$ University of Texas, Austin, Department of Integrative Biology, Austin, TX 78712, USA.

${ }^{c}$ United States Department of Agriculture, Forest Service, Pacific Northwest Research Station, Corvallis, OR 97331, USA.

${ }^{d}$ North Carolina State University, Department of Forestry and Environmental Resources, Raleigh, NC 27695, USA.

Rapid environmental changes expected in the $21^{\text {st }}$ century challenge the resilience of wildlands around the world. The western portion of the Lake Tahoe basin (LTW) in California is an important ecological and cultural hotspot that is at risk of degradation from current and future environmental pressures. Historical uses, fire suppression, and a changing climate have created forest landscape conditions at risk of drought stress, destructive fire, and loss of habitat diversity. We prospectively modeled forest landscape conditions for a period of 100 years to evaluate the efficacy of five unique management scenarios in achieving desired landscape conditions across the 23,600 hectares of LTW. Management scenarios ranged from no management other than fire suppression to applying treatments consistent with historical fire frequencies and extent (i.e., regular and broadscale biomass reduction). We developed a decision support tool to evaluate environmental and social outcomes within a single framework to provide a transparent set of costs and benefits; results illuminated underlying mechanisms of forest resilience and provided actionable guidance to decision makers. Sixteen attributes were assessed in the model after assigning weights to each, derived through a survey of stakeholder priorities, so that the contribution of each attribute to evaluations of scenario performance was influenced by the combined priorities of stakeholders. We found that removing forest biomass across the landscape, particularly when accomplished using extensive fire-based removal techniques, led to highly favorable conditions for environmental quality and promoting overall landscape resilience. Environmental conditions resulting from extensive fire-based biomass removal also 
37 had nominal variation over time, in contrast with strategies that had less extensive and/or used

38 physical removal techniques, namely thinning. Our analysis provided a transparent approach to

39 data assessment, considering the priorities of stakeholders, to provide insights into the

40 complexities of maintaining optimal conditions and managing landscapes to promote ecosystem

41 resilience in a changing world.

42

43 Keywords: decision support; forest management; Lake Tahoe; landscape resilience; scenario

44 planning 


\section{INTRODUCTION}

As society faces a changing climate and the uncertainty that it entails, nearly all sectors (government and private) are working feverishly to understand and mitigate threats to ecological integrity (sensu Cleland et al. 2017) and the persistence of ecosystem function and services (Daily and Matson 2008). The concept of resilience offers a tangible beacon for a future that inevitably will be different, but that also can be ecologically diverse, productive, aesthetic, and meet the needs and desires of society in a sustainable manner. Resilience is the "capacity of a system to absorb disturbance and reorganize while undergoing change so as to still retain essentially the same function, structure, identity, and feedbacks" (Walker et al. 2004). In the ecological literature, outcomes are typically understood as characterizing the state of a system and such characterizations are therefore also commonly understood as evaluating ecosystem integrity, as opposed to ecosystem resilience, for which the focus is on the response of systems to perturbations as a function of ecosystem processes (e.g., Holling 1973, Folke et al. 2002, Gunderson et al. 2010, Walker et al. 2010). As such, resilience only can be truly evaluated after perturbations have occurred, the system has responded, and the outcomes are evaluated.

Lake Tahoe and its basin are rich with biodiversity, aesthetic values (e.g., scenic beauty), and recreational opportunities, that are particularly vulnerable to impacts from climate change. A recent vulnerability analysis commissioned by the California Tahoe Conservancy (California

65 Tahoe Conservancy 2020), and supported by empirical studies (e.g., Coats et al. 2006, Scheller et al. 2018 ), concluded that both the Lake and the upland watersheds are not only vulnerable to changing climates, but are already exhibiting signs of stress and impact. The future of ecological integrity in the Lake Tahoe basin is a core concern across a wide array of stakeholders, including scientists and managers operating in the basin (Chilton 1995, Imperial and Kauneckis 2003, Weible et al. 2005).

Attention paid to Lake Tahoe is largely directed toward the ecological and social value of the basin, but it is also a bellwether for much of the Sierra Nevada mountain range; investments in

74 science and management in the basin are significant compared to most other landscapes in the

75 Sierra, so science-based management solutions are more likely emerge there first (Murphy and 
Knopp 2000, Manley 2004, Hymanson et al. 2010). The Lake Tahoe West Restoration Partnership (LTWRP) is a prime example of a science-based management solution, formed to develop and implement a large-scale landscape restoration strategy across the west side of the Lake Tahoe basin, which ideally could serve as a model for restoration across the basin. The goal of the Lake Tahoe West (LTW) project is to restore the resilience of the forests, watersheds, and communities of the west side of the Lake Tahoe basin to disturbances including wildfire, drought, and climate change. The LTWRP is a multi-stakeholder collaborative initiative lead by the California Tahoe Conservancy, U.S. Forest Service Lake Tahoe Basin Management Unit, California State Parks, Tahoe Regional Planning Agency, and the National Forest Foundation.

Typically, the first step in developing a large-scale restoration strategy is to assess current and potential future conditions, and compare those to desired conditions (e.g., Stanturf et al. 2013). Given the focus of decision makers on sustainability and resilience across multiple social and ecological values, a focus of this study was to evaluate future trajectories under different management scenarios in the face of climate change (Hymanson et al. 2010). Large-scale ecological assessments have many moving parts that make defining the analytical problem, assembling large volumes of data, and evaluating and distilling results challenging. Decision support tools (DSTs) are increasingly used to help managers understand the spatial and temporal variability in conditions across multiple resources, and how best to balance management objectives where they may be in conflict or at least difficult to achieve in an equitable manner (e.g., Bagstad et al. 2013, Vacik et al. 2013, Gordon and Reynolds 2014). DSTs are valuable not only to managers, but they support the entire decision process, which often includes a broad array of engaged stakeholders. DSTs can provide transparency, credibility, trust, and confidence in the decision process, which are critical to successful implementation of management decisions (Reynolds et al. 2014a). project areas and quantify the relative risks and benefits associated with various treatment approaches (Hessburg et al. 2013, Povak et al. 2017). Prioritization of treatment areas is often the objective, with the near-term goal of reducing risk to high value resources. In this study, we 
management activities for improving forest landscape resilience over a long time-horizon. To this end, we evaluated management regimes (in the form of scenarios) conducted over multiple decades across the entire landscape to determine the degree to which landscape resilience had been improved and by what measures.

We developed a DST that provided a unified modeling framework for assembling and evaluating multiple resource conditions over a 100-year timeframe to determine if and how management could promote greater forest landscape resilience across the LTWRP landscape into the future. Three essential tenets of effective decision support solutions (Reynolds and Hessburg 2014, Reynolds et al. 2014b) guided the development of the LTW DST tool and its application: 1) the tool needs to facilitate collaboration among multiple and diverse subject-matter experts and stakeholders; 2) the design of decision models for decision makers needs to formally incorporate the diversity of decision maker perspectives; and 3) the analytical models used need to yield results that are intuitive and accessible to broad stakeholder communities.

\section{METHODS}

\section{Study area}

The Lake Tahoe basin is an 88,000 hectare lake basin that rests between the Sierra Nevada range to the west and the Carson Range to the east along the California and Nevada border, respectively. Lake Tahoe itself sits at $1880 \mathrm{~m}$ in elevation, with the surrounding landscape consisting of over 60 forested watersheds that stretch from the lake shore up to the crests reaching over $3000 \mathrm{~m}$. The LTW landscape consists of the 22 watersheds and approximately 23,600 hectares (59,000 acres) of federal, state, local, and private lands on the western side of the basin from the crest to the lake. The landscape consists of extensive forests and many creeks that course through glaciated valleys and wet meadows before draining into the lake.

The forests on the west side of Lake Tahoe have experienced a high degree of disturbance over

35 the past 100 years. Although they have not experienced the large and severe wildfires that have 36 impacted much of the Sierra Nevada in recent decades (Lydersen et al. 2014, Jones et al. 2016), 37 there have been two fires in the past 15 years: the 2007 Angora Fire that burned over 1200 
138 hectares in the southern part of the basin causing enormous loss of property (Safford et al. 2009),

139 and the 2016 Emerald Fire that burned just over 70 hectares near Emerald Bay, CA. In addition,

140 the basin regularly experiences significant smoke events from fires outside the basin. The basin

141 was extensively logged, beginning in the 1860s during the Comstock silver mining rush in

142 Virginia City in Nevada, and continuing into the $20^{\text {th }}$ century (Lindström 2000), creating a

143 predominantly single cohort of trees, the survivors of which are greater than 100 years old. In

144 recent decades, management has focused on restoration rather than the production of timber,

145 livestock grazing and other consumptive uses.

\section{Management scenarios}

We developed criteria for a range of management approaches to evaluate the effectiveness of the extent, distribution, and type of management treatments for achieving desired conditions. Specifically, management scenarios were developed that addressed three key management options to restore forest landscape resilience: 1) protecting infrastructure, primarily within the wildland urban interface (WUI), versus managing across the entire landscape, including "back

154 country" wilderness areas; 2) forest biomass reduction by thinning versus the use of prescribed

155 fire and managed wildland fire; and 3) management and societal costs and benefits relative to environmental costs and benefits. The result was five management scenarios that ranged from no

157 management, other than fire suppression, to landscape-wide management with various

158 combinations of thinning and prescribed fire (Table 1). This approach reflected decisionmakers'

159 interests in understanding how increases in the pace and scale of treatment would enhance the

160 resilience of Lake Tahoe's social-ecological system (North et al. 2012, Stephens et al. 2014,

161 Manley et al. 2021), and enhance their understanding of inherent tradeoffs associated with

162 management approaches in meeting resource objectives. Specific evaluation criteria and

163 thresholds were developed through collaborations between members of the LTWRP science

164 team (the scientists that conducted the environmental modeling represented here), managers from 165 multiple agencies operating within the basin, and stakeholders representing a range of interests.

\section{Assessing landscape condition}


169 Decision support tools not only support management decisions once data are compiled, but they

170 also provide a framework for organizing information in the initial stages of model building.

171 Thus, an important contribution of our DST to the LTWRP was to provide structure and a

172 process to clarify what resources were most relevant to managers, what conditions were relevant

173 and desired for those resources, and what metrics and values best represented those desired

174 conditions. Resources essential to understanding forest resilience in response to management

175 scenarios were determined by environmental experts, decision makers, and project stakeholders,

176 and included not only resources pertaining to environmental quality (terrestrial and aquatic

177 ecological conditions), but also community values and management operations (Figure 1), which

178 can both drive and limit implementation.

179

180 For each of the three focal areas (environmental quality, community values, and management

181 operations), quantifiable metrics were identified based on available, relevant, and peer-reviewed

182 data sources. The type and number of attributes varied among the three focal areas based on

183 scientific merit (environmental quality), stakeholder priorities (community values), and

184 management considerations (operations). Each focal area is represented by two tiers: topic areas

185 and attributes. A total of 16 attributes were established across the three focal areas (Figure 1).
The 16 individual attributes were in turn represented by one or more metrics of condition. The number of metrics selected to represent each attribute varied based on the complexity of the attribute (see Miller and Saunders 2002, Saunders and Miller 2014), with those associated with environmental quality having the largest suite of metrics, and those associated with community values and operations typically being represented by single metrics (Appendices 1, 2, and 3; see Abelson et al. in review for detailed methods). For example, the quality water topic was represented by two metrics (phosphorus load and fine sediment), whereas biodiversity conservation was represented by 13 metrics representing three focal species of interest, six functional species groups, and four measures of species diversity (Appendices 2 and 3). Subjectmatter experts identified the data that was necessary to evaluate attributes and determined the metric values that corresponded with poor to optimal conditions (Appendices 1 and 4). These values were used in the DST to evaluate forest conditions, propagating from the bottom of the 
199

200

201

202

203

204

205

206

207

208

209

210

211

212

213

214

215

216

217

218

219

220

221

222

223

224

225

226

227

228

229

hierarchy (attributes) to the top (resilience), for each incoming piece of data (Appendix 5)

following methods described in Abelson et al. (in review).

\section{Forest, fire, and climate dynamics}

LANDIS-II modeling was used to simulate management activities and natural processes, and their interaction, over a 100-year period (2010 to 2110) across the entire Lake Tahoe Basin landscape (see Maxwell et al. 2021 this series). In short, above-ground forest dynamics along with nutrient flow, pest outbreaks and climate variability are integrated into a single processbased simulation (Scheller et al. 2019). Five unique LANDIS-II models were run with all model variables being held constant except management activity. The LANDIS-II modeling that provided inputs to the DST was based on a representative concentration pathway (RCP) of 4.5, and averaged outputs from four different global circulation models (GCMs) identified as the most representative of California's hydrology in California's Fourth Climate Change Assessment (Pierce et al. 2018) served as the basis for the future climate projections used in this study: Hadley Center Global Environment Model (HadGEM2), Canadian Earth System Model (CanESM), Centre National de Recherches Meteorologiques (CNRM5), and Model for Interdisciplinary Research on Climate (MIROC5). The outputs of the LANDIS-II modeling for the LTW landscape were then used by topic-area specialists to quantify the metrics used to represent each of the 16 attributes in our DST to evaluate scenario performance (Table 2). In an important sense, the evaluation conducted in this study reflects both integrity and resilience because, although we evaluated management performance in terms of outcomes, most of the model inputs were derived from the process-based LANDIS-II system, which dynamically models the evolution of system states over time based on the simulation of processes (Scheller et al. 2019).

\section{Decision support tool development}

We focus here on how values derived for attributes were prioritized by stakeholders and how the interaction of priorities, current conditions, future climate, and management resulted in the overall performance of each of the five management scenarios (Table 1). Conditions across such 
230 a wide array of resources within a landscape could be considered equally important, but that is

231 rarely the case. Most often, individuals and institutions have specific priorities at any specific

232 point in time, motivated, for example, by perceived need, concern, risk, or institutional missions.

233

234 We used multi-criteria decision analysis (MCDA; Kamenetsky 1982, Saaty 1994, Mendoza et al.

235 2006, Murphy 2014) to compare the performance of the five scenarios in terms of the desired

236 condition outcomes established for the 16 attributes associated with the three focal areas (Figure

237 1, Appendix 1). The performance scores of the multi-criteria decision model (MCDM) in EMDS

238 are derived by the decision engine of Criterium DecisionPlus (Murphy 2014). Criterion weights

239 in the decision hierarchy were derived using Saaty's (1994) pairwise comparison methods in the

240 Analytic Hierarchy Process (AHP). Using moderated discussion groups, we convened a group of

24124 stakeholders (National Forest Foundation 2019) to derive the relative weighting of the 16

242 attributes in our DST (Abelson et al. in review). Stakeholders also rated the utility of each of the

24316 attributes using the Simple Multi-Attribute Rating Technique (SMART; Kamenetsky 1982),

244 where the utility of an observed value for each attribute indicates how well the observed value

245 contributes to the model's (Figure 1) overall performance score.

247 Weights are calculated on a scale of 0 to 1 , and sum to 1 at each level of the hierarchy, starting

248 with the 16 attributes. The weighting assigned to the attributes ranged from a low of $1 \%$ to a high

249 of $15 \%$ (Figure 1), with six attributes carrying $78 \%$ of the weight: water quantity (15\%), quality

250 water (15\%), wildlife conservation (13\%), functional fire (13\%), fire threat to property (11\%),

251 and wildland-urban interface fire (11\%). The remaining 10 attributes carried a total of $22 \%$ of

252 the weight and individually were assigned weights equivalent to $\leq 5 \%$. Attribute weights

253 propagate up through each level of the hierarchy (Figure 1). The primary objective of the LTW

254 project was to improve environmental quality, and this is reflected in the environmental quality

255 focal area being weighted most heavily at $59 \%$ of the evaluation. In contrast, community values

256 carried $29 \%$ and operations carried $12 \%$ of the weight in the evaluation.

257

258 Scenario performance scores 
MCDM performance scores were derived by evaluating conditions for the 16 attributes for each the five alternative scenarios at each of 10 time steps, and these results were plotted and summarized. The overall performance score of each scenario was calculated in CDP as the sum of products of the attribute weights (range $=0$ to 1 ) and their utility scores (range $=0$ to 1 ), which then carried through each level of hierarchy such that performance can be evaluated at any level.

Performance scores range from 0 to 1 ; scores close to 1 indicate that conditions are optimal because they are approaching the target desired conditions, whereas scores close to 0 indicate suboptimal conditions because they are deviating from target desired conditions. We divided the range of values from 0 to 1 into five intervals of 0.2 to aid in the interpretation of differences in performance among scenarios (Table 3). We used both quantitative and qualitative approaches to compare the performance of scenarios with respect to maintaining or achieving desired conditions. Quantitative metrics included the mean, standard deviation, range (i.e., minimum and maximum values) in performance scores for any given level of the hierarchy, as well as the number of decades above a specified threshold (i.e., 0.8 or 0.6). Standard deviation and range can be informative to decision-makers because predictability may be more important in some situations (e.g., it may be preferable to have a scenario that slightly underperforms over the full temporal trajectory but does not have large year-to-year swings in forest condition). Qualitative metrics rank and compare scenarios regarding their relative performance compared to other management scenarios, both at any given time point and across temporal trajectories.

\section{Sensitivity analysis}

CDP models output sensitivity statistics (originally described for AHP models by Saaty 1994). In the case of our CDP modeling, the sensitivity analysis was repeated at each 10-year time step to assess model sensitivity over the 100-year period for each management scenario. The key metric produced by the sensitivity analysis is criticality, which is the absolute percent change in a criterion weight that would cause the top-rated scenario in our analysis results to be replaced by another scenario. CDP output, like most commercial MCDMs that implement the AHP, provides a criticality score for all attributes. The criticality score is a measure of model sensitivity in the 
291

292

293

294

295

296

297

298

299

300

301

302

303

304

305

306

307

308

309

310

311

312

313

314

315

316

317

318 (Scenario 1) came close to marginal performance. The remaining scenarios, in descending order

319 of performance, were Scenario 3 and Scenario 4, both with mean performance scores of 0.68 (SD

$320=0.05, \mathrm{SD}=0.04$, respectively $)$, followed by Scenario 2 with a mean value of $0.63(\mathrm{SD}=0.07)$

sense that the identification of the top-rated scenario may be sensitive to how the attributes have been weighted. Low values of criticality indicate high model sensitivity to the associated attribute, and, conversely, high criticality values indicate relative model robustness (e.g., insensitivity). A simple way to assess model robustness is to examine the criticality value of the most sensitive attribute. The long-standing and well-accepted heuristic for judging robustness was proposed by Saaty (1994) as a criticality value of at least 10 percent for the most sensitive criterion. We follow this convention in assessing the robustness of our CDP models in the results.

\section{RESULTS}

\section{Overall scenario performance}

Relatively speaking, Scenario 5 (extensive fire-based approach, Table 1) outperformed all other scenarios, while Scenarios 1 and 2 consistently underperformed (Figure 2, Appendix 6). Overall, the five scenarios formed three clusters: Scenario 1 (fire suppression only) and Scenario 2 (wildland-urban interface focus) had similar and the lowest performance scores that trended together over time. Scenario 3 (thinning-based approach) and Scenario 4 (fire-based approach) trended together with moderate performance scores, while Scenario 5 consistently stood alone with the highest performance values. Specific aspects of overall scenario performance are explored below.

\section{Mean performance of scenarios}

Scenario 5 was the best performing scenario based on the mean performance score $($ mean $=0.78$, $\mathrm{SD}=0.07$ ), indicating nearly optimal performance across the 100-year period (Figure 2;

17 Appendix 6). All other scenarios had good performance scores, but the lowest scoring scenario 
321

322

323

324

325

326

327

328

329

330

331

332

333

334

335

336

337

338

339

340

341

342

343

344

345

346

347

348

349

350

351

and Scenario 1 with a mean value of $0.62(\mathrm{SD}=0.06)$. The variance of these estimates indicates that Scenarios 1-4 were not well differentiated in their performance.

\section{Year-to-year variation in scenario performance}

Variation over time reflects uncertainty in management outcomes, so lower year-to-year variation is most often preferable. In general, year-to-year variation within scenarios was low, with standard deviations being $\leq 10 \%$ of mean values. In the first 80 years, Scenarios 3, 4, and 5 were relatively stable with regard to inter-decadal variability; in contrast, Scenarios 1 and 2 were considerably more variable (Figure 2).

Scenario 4 resulted in forest conditions that had the least year-to-year variation $(\mathrm{SD}=0.039)$.

Over the first 80 years, Scenario 5 had the lowest variability $(\mathrm{SD}=0.016)$, however conditions deteriorated in year 90 with only a slight recovery in year 100. As a result, Scenario 5 had a nearly the highest standard deviation ( $\mathrm{SD}=0.065$ ) across full the 100-year time frame. Scenarios 3 and 1 had intermediate standard deviation values of 0.053 and 0.059 , respectively. Scenario 2 had the largest standard deviation value of 0.074 .

\section{Residency time in condition classes}

Another facet of performance is the amount of time that conditions meet or approach desired target conditions, particularly when desired conditions are expected to be most resilient to disturbance. In general, residency times in good and optimal conditions were greater with increased management and increased use of fire (Figure 2). Scenario 5 (extensive use of fire) had the greatest number of decades in optimal $(n=7)$ and good $(n=3)$ conditions over the 100year period evaluated. Scenario 4 (use of fire) had the next highest residency times associated with desired conditions, with no decades in the optimal condition but all 10 decades in the good condition. Scenario 3 (primarily thinning) performed almost as well as Scenario 4, with all but one decade resulting in good conditions. Scenarios 1 and 2 performed the worst by this measure: Scenario 2 had eight decades in the good range and two in the marginal range, while Scenario 1 had seven decades in the good range and three in the marginal range. 


\section{Focal area outcomes and contributions to scenario performance}

Scenario performance was a function of the conditions of each of the three focal areas component parts of the system are faring, in addition to overall performance. For example, the same mean performance score of "good" could result from two very different landscape conditions: 1) all three focal areas are in good condition; or 2) one focal area is in poor condition and the other two are in optimal condition. Here we delve into how individual focal area conditions contributed to the observed overall performance of each scenario.

\section{Environmental quality}

366 Environmental quality was the primary objective of the Lake Tahoe West project, and consequently it was weighted (and contributed) the most (59\%) to overall scenario performance (Figure 1). Scenario 5 (extensive fire) outperformed all other scenarios with little variation between decades (Figure 3, Appendix 6). Environmental quality remained within an optimal range under management Scenario 5 over the entire century with nominal variation (mean =

372 but not optimal, environmental quality. Scenario 3 produced performance scores with a mean

373 value of $0.72(\mathrm{SD}=0.014)$, and Scenario 4 performed slightly worse with a mean value of 0.68

$374(\mathrm{SD}=0.030)$, reflecting their associated intermediate management inputs. Scenarios 1 and 2

375 (limited management) performed the worst, but were still in the good range (mean $=0.65, \mathrm{SD}=$ 0.042 and mean $=0.62, \mathrm{SD}=0.044$, respectively), with higher between-decade variability

377 (periodic drops into the marginal condition range). period, regardless of the management scenario, as reflected in the small standard deviation

381 values for mean performance scores. This indicates that management is, or at least can be, the 
383

384

385

386

387

388

389

390

391

392

393

394

395

396

397

398

399

400

401

402

403

404

405

406

407

408

409

410

411

412

413

with forest ecosystems in the Lake Tahoe West landscape. Another salient aspect of performance was the consistent relative ranking of scenario performance in environmental quality over time. Specifically, for nearly every decade, Scenario 5 was the highest ranked scenario followed by Scenarios 3, 4, 2, and then 1 .

Environmental quality was represented by two topics: terrestrial and aquatic environmental quality, both of which carried equal weight in representing environmental quality (Figure 1). For terrestrial environmental quality, two of the three attributes carried most $(86 \%)$ of the weight functional fire and wildlife conservation. For aquatic environmental quality, the two attributes (water quality and quantity) carried equal weight. Because of the relative equity of the topics and all but one of the attributes (44-50\% of the weight other than upland vegetation health with just $14 \%$ of the weight), environmental quality condition scores truly reflect a composite of conditions, as opposed to some version of stakeholder priorities. In terms of scenario performance, terrestrial conditions started and remained good to optimal over the course of the century $(\min =0.69, \max =0.93)$, regardless of management scenario $(\min$ mean $=0.74, \max$ mean $=0.89$ ). Differences in terrestrial conditions were largely driven by functional fire, which was the only one of the three attributes that varied in condition class over time $(\min =0.52, \max$ $=0.93$ ), and varied by management scenario $($ min mean $=0.66$ for Scenario1, max mean $=0.88$ for Scenario 5). Aquatic conditions varied slightly more over the course of the century from mediocre to optimal $(\min =0.45, \max =0.93)$, and similarly by management scenario (min mean $=0.53$ for Scenario 1 , max mean $=0.88$ for Scenario 5 ). Within aquatic conditions, water quality was uniformly optimal, whereas water quantity was much more variable, ranging from poor to optimal $(\min =<0.01, \max =1)$, and driven strongly by management scenario (mean $=0.13$ for Scenario 1 , max mean $=0.88$ for Scenario 5 ).

\section{Community values}

The community values were an important but secondary focal area in the Lake Tahoe West landscape restoration project, and as such it carried $29 \%$ of the weight in overall scenario performance (Figure 1). Overall, the more management intensive scenarios (Scenarios 3, 4, and 5) performed well, resulting in generally good conditions over most of the entire century. 
414 Scenario 3 performed the best $($ mean $=0.69, \mathrm{SD}=0.10)$, followed closely by Scenario $5($ mean $=$

$4150.68, \mathrm{SD}=0.18)$ and Scenario 4 (mean $=0.67, \mathrm{SD}=0.07)$. The variation within scenarios was

416 high, making the performance of these top three scenarios indistinguishable. Scenarios 1 and 2

417 were more variable, which resulted in mediocre overall performance. $($ mean $=0.57, \mathrm{SD}=0.15$,

418 and mean $=0.53, \mathrm{SD}=0.11$, respectively). Again, variation in performance within these two

419 scenarios was high, obscuring differences in their performance.

In terms of residency time in desired conditions, Scenario 5 outperformed the other scenarios for community values over the first eight decades, although conditions steadily dropped from optimal in year 10 to good in year 80. Performance scores for all but Scenario 5 increased in the eighth decade. In year 90, while all scenarios have declining conditions, Scenario 5 dropped precipitously from good conditions to poor conditions.

Another interesting aspect of performance in community values was that, unlike environmental quality, the year-to-year variation in the community values focal area was not synchronous among scenarios (Figure 4). The best performing scenario in any given decade shifted frequently over time. For example, Scenarios 1 and 2 showed a large drop in performance in year 60, while Scenario 5 remained stable. In year 90, all scenarios experienced a drop in performance but the drop in Scenario 5 (0.41) was markedly more substantial than the other scenarios (ranging from 0.14 to 0.31 ; Appendix 6). This temporal variability in performance suggests that community values (as defined in this project) are more vulnerable to conditions created by dynamic processes and stochastic events as modeled in our landscape.

Community values were represented by two topic areas, with health and safety carrying $83 \%$ of the weight, and social values (carbon sequestration, recreation impacts from emissions, cultural resource quality, and wood byproducts from restoration) carrying only $17 \%$ of the weight (Figure 1). Thus, social values in this analysis, despite the widely held importance put on carbon 441 sequestration (Forest Climate Action Team 2018) and cultural resources (Long 2019, Long et al. 442 2020) in particular, had limited influence on overall performance scores. For cultural resource 443 quality, Scenario 5 was the only stand out, with good performance (mean =0.64) compared to poor to suboptimal performance for all the other scenarios. None of the scenarios performed well 
445 for carbon sequestration, with Scenarios 3 and 5 having suboptimal performance (mean $=0.34$

446 and 0.23 , respectively), and the remaining scenarios having better but only marginal performance

$447 \quad$ (range $=0.49$ to 0.55 ).

448

449 Health and safety was represented by three attributes (Figure 1), two of which equally carried a

450 total of $88 \%$ of the weight (wildland urban interface [WUI] fire risk and fire threats to property).

451 WUI fire risk was the primary attribute driving observed performance scores for community

452 values. It varied widely from poor $(\min =0)$ to optimal $(\max =0.97)$ over time, and varied

453 among scenarios although generally declined over time across all scenarios (min mean $=0.26$ for

454 Scenario 1 , max mean $=0.55$ for Scenario 5) indicating a strong influence of climate on fire risk

455 in the WUI. Risks to property varied over time from suboptimal to optimal $(\min =0.33, \max =$

456 1.0), but retained mean performance values of optimal across all scenarios ( $\min$ mean $=0.87$,

457 max mean $=0.97$ ), indicating that realized risk to property is episodic in the form of infrequent

458 but high impact events. Quality air, the third attribute, varied widely in conditions over time

459 (poor to optimal) and among scenarios (marginal to optimal), it had little influence on

460 performance.

461

462

\section{Management operations}

463

464 The management operations focal area was assigned the lowest importance, carrying just $12 \%$ of

465 the total model weight (Figure 1). It exhibited unique and somewhat opposing scenario

466 performance relative to the other two focal areas (Figure 5, Appendix 6). Generally, scenario

467 performance declined with greater management input, primarily reflecting the cost of

468 management. Mean scenario performance in the operations focal area was led by Scenario 1 with

469 an optimal performance score of $0.83(\mathrm{SD}=0.07)$, in contrast to community values and

470 environmental quality focal areas, whereas Scenario 1 performed the worst or second worst of all

471 the scenarios. The remaining scenarios generally followed degree of management input:

472 Scenarios 4 and 2 with good performance (mean $=0.74, \mathrm{SD}=0.06$, mean $=0.68, \mathrm{SD}=0.12$ ),

473 followed by Scenario 5 with marginal performance and high variability (and mean $=0.56, \mathrm{SD}=$

4740.11 , respectively), and finally Scenario 3 with suboptimal performance and high variability

$475($ mean $=0.48, \mathrm{SD}=0.14)$. Like the community values focal area, there was variability in the 
relative ranks of the scenario's performance over time, with frequent shifts in relative performance from decade to decade. Notably, Scenario 5 was most often ranked nearly the lowest for operations, but was most often ranked the highest for the other two focal areas.

Management operations were represented by two topic areas that carried equal weight: economics and feasibility (Figure 1), although recall that management operations itself only carried $12 \%$ of the weight, so the contribution of individual topic and attribute conditions was minimal. Economics varied widely from poor $(\min =0)$ to optimal $(\max =0.83)$, but varied less among scenarios from marginal to barely optimal $(\min$ mean $=0.53$ for Scenario 3 , max mean $=$ 0.82 for Scenario 4). Within economics, the two attributes were treatment costs and suppression costs, with suppression costs carrying nearly all (83\%) of the weight. However, suppression costs did vary widely over time $(\min =0, \max =0.98)$ and by scenario from marginal to barely optimal $(\min$ mean $=0.62$ for Scenario 2, max mean $=0.82$ for Scenario 4). Interestingly, if net treatment costs (cost of removing material minus its market value) had been weighted more heavily, it would have been one of the few instances where Scenario 3 performed poorly, and the lowest ranked among all the scenarios (other than no management) with a mean score of 0.19 . The remaining three scenarios were rated as good and were nearly identical in their mean performance scores (Scenario $2=0.71$, Scenario $4=0.76$, Scenario $5=0.60$ ). Finally, feasibility varied widely from suboptimal $(\min =0.33)$ to optimal $(\max =1)$ and among scenarios $(\min$ mean $=0.35$ for Scenario 5 , max mean $=1.0$ for Scenario 1). Within feasibility, the two attributes were staffing and days of intentional burning, with staffing carrying the majority (67\%) of the weight. Staffing varied to a degree over time, ranging from suboptimal $(\mathrm{min}=0.29)$ to marginal ( $\max =0.69)$, and it ranged more widely among scenarios from suboptimal (min mean $=0.36$ for Scenario 3$)$ to good $(\max$ mean $=0.72$ for Scenario 4$)$, which is not surprising given that management investments were held fairly constant over time within scenarios.

\section{Robustness of the decision model}

We summarize the sensitivity analyses of the MCDM model results by the ten time steps (Table 4). Consistent with earlier results (Figure 2), Scenario 5 was the top-ranked scenario of the five management scenarios across all time steps except year 90, at which point Scenario 4 was the 
highest ranked scenario. Criticality values exceeded Saaty's (1994) $10 \%$ threshold heuristic for years 10 through 80, indicating a high degree of confidence in identifying Scenario 5 as the best performing scenario up through year 80 . At years 90 and 100, the criticality statistic dropped to nearly $1 \%$, indicating that a change in weight of the most sensitive focal area could readily shift away from Scenario 5 being the best performing scenario later in the century, when conditions become more variable. Management operations was the most sensitive focal area for most of the century (Table 4), meaning a sufficiently large change in its weight would cause Scenario 5 to be replaced as the top ranked alternative in years 10 through 80 by another scenario for a given decade (Table 4); however, as already noted, the criticality results for years 10 through 80 indicate a robust model with Scenario 5 ranked highest in performance in this period. In contrast, in years 90 and 100, the criticality scores indicate that we could not practically distinguish between Scenarios 4 and 5 as the top ranked alternative.

\section{DISCUSSION}

Management activities influence forest dynamics over long time-horizons and are increasingly essential for cultivating resilient forest landscape conditions. The decision support tool (DST) that we developed using EMDS demonstrated that management investments can make a substantial difference in creating and maintaining desired forest landscape conditions over time across the westside of the Lake Tahoe basin, despite a changing climate. Specifically, forest landscape conditions benefitted substantially by management activities that reduced woody biomass through thinning and intentional fire, resulting in a more productive role of fire as a natural process (i.e., functional fire), wildlife habitat conservation, and improved water quantity and availability (Figure 6). The DST enabled the transparent assessment of many complex, and often compensatory, attributes that were informed by considering forest and climate dynamics 100 years into the future. Model transparency also provided many insights into how stakeholder priorities can greatly affect the outcomes and perceived effectiveness of various management approaches.

\section{Landscape-wide management is important}

Our analysis results resoundingly showed that increasing the extent of management across the landscape (as represented by Scenarios 1 to 5) improved the achievement of desired outcomes 
537 (Figure 6). We found substantial differences among the management strategies in terms of their

538 influence on landscape conditions, and environmental quality, in particular, over the course of

539 the $21^{\text {st }}$ century in markedly different ways. Performance closely followed the extent of

540 management across the landscape - the greater the number of acres treated, the more positive the

541 outcome for environmental quality based on the performance score. This is consistent with other

542 studies that found that treating large landscape areas would mitigate impacts of severe wildfires

543 (Moghaddas et al. 2010). Stevens et al. (2016) conducted a similar study in the northern portion

544 of the LTW landscape, and although they used a different fire and vegetation modeling

545 framework and did not incorporate climate change, they also found that more management

546 treatment had beneficial effects by reducing the prevalence of high severity wildfire.

547 In Lake Tahoe, as throughout California and the western U.S., the threat of wildfire to forests,

548 property, and people has become a primary driver in forest management, with the primary

549 objective being to reduce the probability that large, high severity fires will occur (Hessburg et al.

550 2016). Our results showed that forest management treatments consisting of thinning and/or

551 prescribed fire were effective at reducing the risk and probability of significant and destructive

552 wildfires. Scenarios 1 and 2 were more variable; this in part reflects that extreme wildfires in one

553 period may inhibit the incidence of fire in the same area for many years, while more dispersed

554 treatments and fires tend to moderate fire effects over time (e.g., Scholl and Taylor 2010, Perry

555 et al. 2011). This finding is consistent with previous synthesis work (e.g., Long et al. 2014) and

556 landscape modeling in the region (e.g., Krofcheck et al. 2017). Previous research (Ager et al.

5572010,2013 ) had found that concentrating treatments in smaller areas, such as the WUI, could

558 reduce the risk of damage in those areas (including buildings), but at the expense of greater loss

559 of old trees in the untreated areas.

560 The two most aggressive treatment scenarios (Scenarios 3 and 5) treated approximately 7\% of

561 the landscape each year, or roughly 50-70\% of the forested landscape per decade (locations can

562 be treated more than once per decade), which equates to a 20 -year disturbance frequency. This is

563 consistent with historic fire return intervals. Previous research has suggested that gains in

564 performance in some metrics, such as fire and carbon outcomes, can be achieved by targeting

565 treatments to the areas at greatest risk of high-severity fire (Stevens et al. 2017, Krofcheck et al.

566 2017). 


\section{Superior performance of landscape fire as a management tool}

568

569

570

571

572

573

574

575

576

577

578

579

580

581

582

583

584

585

586

587

588

589

590

591

592

593

594

595

596

One of the most important results of our analysis was that the expanded use of fire as a management tool to reduce forest biomass, as represented by Scenario 5, was consistently superior to other management approaches in achieving and maintaining optimal desired conditions, particularly regarding environmental quality and overall condition (Figure 6). In addition to reflecting the ecological benefits of fire, as reported by others (e.g., Agee and Skinner), the strong ecological performance of Scenario 5 was bolstered by the emphasis (i.e., weights) that stakeholders put on the importance of increasing functional fire and reducing the risk of large, high severity fires (particularly in the WUI) while placing relatively low emphasis on the cost and logistics of treatments (e.g., restrictions on when burning is permitted) (e.g., Kolden 2019). The results from these analyses provided a scientific foundation for managers to propose a gradual increase in the use of fire as part of their restoration strategy for Lake Tahoe West (Lake Tahoe West Restoration Partnership 2019).

Stability did not explicitly alter performance scores of management strategies directly, but some ecological processes (e.g., persistence of species at risk of local extirpation), and many aspects social well-being (e.g., consistent conditions to which people can adapted versus periodic significant impacts) favor stability (Angeler and Allen 2016, sensu Johnstone et al. 2016). We found that scenarios that treated smaller proportions of the landscape per year and treatments that were more concentrated around the WUI showed greater variability in landscape conditions over time. Consistent with other studies (e.g., Maxwell et al. 2020), this outcome appeared to be a function of the greater probability of large and high severity wildfires when smaller proportions of the landscape were receiving management inputs in the form of thinning or fire. Frequent low to moderate severity fire is particularly effective in reducing the risk of future high severity fires in any given area (Omi and Martinson 2004, Arkle et al. 2012). Scenarios that extensively used prescribed burning (Scenario 5 in this study) performed well in terms of achieving desired conditions, as well as producing stable and reliable condition outcomes (i.e., low variability over time and low sensitivity to weighting) over the course of at least the first 80 years.

Fire as a management tool has many advantages, which were reflected in the performance of Scenario 5, but also has some disadvantages, which although they were given lower weight by stakeholders, are still recognized as important. Prescribed fire as a tool results in smoke 
597

598

599

600

601

602

603

604

605

606

607

608

609

610

611

612

613

614

615

616

617

618

619

620

621

622

623

624

625

emissions, which are less impactful than wildfire, so shifting toward intentional fire can result in a net benefit in terms of reduced public health impacts (Long et al. 2018, Schweizer and Cisneros 2016). Our modeling also indicated that use of fire was less expensive than thinning, although this carried minimal weight in the evaluation. Challenges with using prescribed fire include having a sufficient number of allowable burn days (based on suitable weather conditions and air quality) and adequate staffing to accomplish the work - both of which are commonly limiting factors in implementation (Ryan et al. 2013). In our model, stakeholders considered feasibility a low priority so, although feasibility is the primary reason more burning is not accomplished (Kolden 2019), it did not substantially downgrade the performance of the extensive burning scenario. The decision model helped highlight two important outcomes: 1) that given sufficient social license and commitment of resources, optimal environmental outcomes can be achieved but only through the use of extensive fire; and 2) knowing that desired conditions can be achieved may, in turn, help agencies and communities rally to overcome the social barriers to its implementation (McCaffrey et al. 2013).

\section{End of century variability and uncertainty}

Dynamic modeling requires parameterizing many processes and interactions, based primarily on estimates derived from empirical studies (Seidl 2017). Future climate conditions are also estimates based on modeling and this introduces even greater uncertainty as it is not certain which of the multiple plausible future conditions are most likely to occur (Scholes et al. 2014). The value in longer-term modeling is to look for trends, thresholds, tradeoffs (Kim et al. 2017). We modeled a 100-year period to explore trends and variability within and among management scenarios, but the uncertainty in how climates will change over this time frame makes observed dynamics in later decades less reliable. In our study, we found instabilities in later decades for the community values and management operations focal areas. Specifically, in year 80 and 90 we observed declines in the more aggressive management scenarios. Scenario 5's decline in year 90 was due to the interaction of the prescribed fire parameterization and the repetition of 2100 climate conditions out to 2110 (due to lack of climate modeling data after 2100), and, as such, may reflect model anomalies.

\section{Influence of stakeholder priorities on perceived management performance}


626 In our DST, community values and operations (together comprising $41 \%$ of the total model) did 627 not carry as much weight as ecological considerations (which alone comprised 59\% of the 628 model) though they still played an important role (Figure 1). While environmental conditions 629 over the course of the century showed a clear and consistent positive response to expanded 630 treatment and expanded use of fire, variable (and sometimes compensatory) responses over time 631 were observed in community values and operations (Figures 4 and 5). A main finding was that 632 management scenarios that did not reduce densities of small trees and associated fuels resulted in 633 landscapes that were prone to more severe fire events, which then set in motion larger 634 oscillations between poor and good community values and operational conditions. While 635 wildfires can be an effective fuel reduction tool, managers are increasingly concerned that 636 uncharacteristically severe wildfires will result in long-lasting losses of social and ecological 637 values (e.g., Spies et al. 2019).

638 The aquatic topic area was weighted heavily by stakeholders, accounting for $50 \%$ of 639 environmental quality. This is likely to reflect the exceptional importance of restoring and 640 maintaining the clarity of Lake Tahoe, although most efforts to date have focused on urban 641 sources of impact rather than forest lands (Riverson et al. 2008). Our DST used LANDIS-II 642 projections (Scheller et al. 2018) for leaf-area-index (LAI) as the proxy for water quantity, and 643 scenarios with increased thinning and burning treatments (both of which reduce LAI through 644 removal of live biomass) performed well. Although increased management activity modestly 645 increased loading of fine sediment particles and phosphorus, those increases generally offset 646 loads from wildfires; as a result the differences across scenarios were not substantial. For 647 example, previous studies have found that increased treatments can realize benefits to aquatic 648 systems by mitigating wildfire impacts to water quality (Buckley et al. 2014) and increasing 649 water yield (Roche et al. 2020). Further, results of hydrologic modeling conducted in the study 650 area indicated that thinning small trees (up to $20 \mathrm{~m}$ tall) would reduce LAI and also increase 651 snow accumulation and melt volume (Krogh et al. 2020), further enhancing water quantity.

652 While our results suggest that managers in the basin ought not to expect substantial 653 improvements in water quality from forest management, it importantly indicates that water 654 quality concerns do not limit larger restoration efforts. Our results indicated that both water 655 quality and quantity were likely to degrade in the future without broad-scale use of fire 656 (Appendix 6), which provides compelling evidence to overcome near-term concerns about the 
657 impacts of forest treatments, fire in particular, on Lake Tahoe's water clarity. Our findings add to

658 the growing body of literature (e.g., Nair and Howlett 2016) that indicate that effective

659 approaches to promoting long-term ecosystem resilience focus on longer time-frames, adapting

660 to change, and consider a wide range of interacting values, as opposed to a focus on near-term

661 risk reduction and maintaining the status quo.

662 Both the attributes of community values and operations had high year-to-year variability, and to 663 some extent gains in community values are compensated by losses in operations. That is, while

664 Scenario 1 generally performed poorly (and Scenario 5 generally performed very well) regarding

665 the community values because of the high risk of property damage, the opposite was true for the

666 performance of management operations because the suppression-only scenario was less

667 expensive in terms of implementation costs. Various studies have suggested that suppression-

668 only strategies fail to account for the full social costs of future disturbances (Buckley et al. 2014,

669 Bagdon and Huang 2016), and that restoration-based strategies can achieve social and ecological

670 win-win outcomes (Bagdon et al. 2016, Spies et al. 2019).

671 In the DST, environmental outcomes were weighted nearly 2:1 over social and economic

672 outcomes. As a result, management activity was favored over management costs, and

673 environmental outcomes over feasibility. For example, increasing treatments were needed to

674 mitigate impacts from future wildfires, but the type and extent of management were not

675 substantially tempered by factors other than environmental outcomes. These choices were made

676 intentionally to help ensure that strategies would promote ecological resilience without being

677 unduly constrained by policies, regulations, and other institutional limitations (e.g., Stephens et

678 al. 2013, Schoennagel et al. 2017) However, if community values and management operations

679 had been given more weight, it is likely that Scenario 5 may not have been as much of a standout

680 in terms of performance, perhaps Scenario 4 would have fared as well or better, as reflected in

681 the sensitivity analysis (Table 4), and Scenario 3 probably would perform more poorly, given the

682 high cost of thinning. In short, there is no gain (progress) without pain (cost by some measure).

683 Another study of forest landscape collaboratives found that social values often received less

684 attention than ecological ones, and that participants were sometimes discouraged when projects

685 were planned that were proved economically infeasible (e.g., Urgenson et al. 2017); they

686 suggested that clear articulation of tradeoffs is important. 


\section{Decision support for landscape resilience}

688

689

690

691

692

693

694

695

696

697

698

699

700

701

702

703

704

705

706

707

708

709

710

711

712

713

714

715

716

EMDS has been used since the late 1990s to provide decision support for numerous management issues related to environmental analysis and planning (Reynolds et al. 2014 and work cited therein), but its application to the LTW resilience project is novel. Whereas previous applications have been point-in-time analyses based on the current observed state of ecosystems (e.g., Cleland et al. 2017, Hessburg et al. 2013), the LTW DST considers the evolution of ecosystem states over a 100-yr timeframe based on the LANDIS-II process model. Examining a long timehorizon provided a framework for an analysis of ecosystem resilience (Holling 1973, Walker and Salt 2010) in the sense discussed in the Methods section. The LTW resilience analysis was facilitated by a new EMDS workflow (Chappell 2009) component that automates model processing by invoking sequences of models as activities and by using iterative loops. To avoid belaboring the details, we simply note that workflow automation reduced the task of performing many model runs to pressing a button to execute all the required models. For an in-depth discussion of the workflow as implemented in the LTW DST, see Abelson et al. (in review).

In other respects, however, the LTW DST is similar to other EMDS applications in its use of knowledge-based reasoning (Walters and Neilson 1988) to assess ecosystem states and evaluate alternative management scenarios. Especially in the past 20+ years, analyses and assessments in decision support have increasingly turned to knowledge-based methods to address contemporary management issues related to the sustainability, integrity, and resilience of ecosystems because these are large, complex, and abstract topics that are not easily modeled using traditional scientific analytical tools (Swanson and Greene 1999, Gunderson 1999, Reynolds 2001). Both of the analytical tools applied to the LTW resilience analysis (NetWeaver and CDP) are knowledge-based systems, which are useful in complex analytical contexts because, essentially, if one can reason about the problem at hand, then it can be modeled.

Here, we focused on CDP in particular because our primary objective here was to evaluate the performance of the five management scenarios (while NetWeaver was principally used to preprocess complex data before inclusion in the CDP model). A virtue of MCDMs in general, and CDP in particular, is that they are rationale, transparent and repeatable (Murphy 2014). That said, MCDM models typically operate at the interface between science and policy and have an inherent, unavoidable element of subjectivity because they require judgments from decision 
717 makers as to the relative importance of the criteria (i.e., the focal areas and topics in our

718 analysis). Indeed, there is no such thing as a value-free decision in environmental management.

719 Deciding what topics matter, and how much they matter, are critical in the design of an MCDM

720 for decision making in general, and decision making in environmental management in particular.

721 The sensitivity analysis for the LTW model of scenario performance (Table 4) is helpful in

722 balancing subjectivity on the one hand and a rational, transparent, and repeatable model on the

723 other, because it highlights those model weights that are most sensitive to determining the

724 relative ordering of performance scores, and this is useful to focus discussion about choices that

725 have been made in MCDM weights.

\section{CONCLUSION}

727 Interdisciplinary modeling is becoming an essential feature of bringing the best available 728 information to bear on landscape restoration planning and implementation. This is largely driven

729 by observed and projected future climate change, and the threat it poses to long term

730 sustainability and resilience of ecological and social systems. Future dynamics and possible

731 characteristics and impacts of extreme events, as well as chronic stress from directional change

732 in temperature or precipitation, are essential to attempt to understand (at least in terms of

733 bounding what is probable). However, the ways in which climate change will alter landscapes

734 and ecological perturbations are not fully understood, and projections of future conditions and

735 dynamics become less reliable the further out in time they go. Decision makers rarely make

736 project-level decisions that commit to implementation spanning more than 5 to 10 years, and

737 they are likely to change their management approaches in response to environmental outcomes

738 over time. Consequently, decision-makers may be not be overly concerned with projections of

739 future declines, so long as the strategy improves conditions in the near-term and maintain options

740 for avoiding damaging losses in the long-term. Such an approach can be successful, provided

741 that the management system is also designed to monitor and adapt to changing conditions in a

742 timely manner.

743 Our modeling effort helped managers to consider a wide range of social and ecological values

744 over multiple decades. Ultimately, the Lake Tahoe West restoration strategy proposed by

745 LTWRP (Lake Tahoe West Restoration Partnership 2019) focused on increasing thinning

746 treatments across the landscape while gradually ramping up the use of prescribed fire. This 
747 choice represented a mix of Scenarios 3, 4, and 5, which our model all suggested would promote

748 greater ecological and social values over the status quo management approach (Scenario 2). Our

749 decision framework identified the effects of climate change and different management strategies

750 on resilience over multiple decades in addition to the consideration of tradeoffs among

751 stakeholder values; taken together this helped decision makers avoid the trap of management

752 informed only by short-term gains. This work also provided scientific understanding of the

753 potential benefits and downsides of increasing the use of intentional fire. The use of such an

754 integrated modeling system helps managers and stakeholders to envision the challenges they will

755 face in addressing dramatically changing future conditions and garnering support for

756 implementing new management approaches. It also provides a ready-made system for evaluating

757 management effectiveness, evaluating system conditions, and monitoring progress toward

758 greater resilience.

759

\section{ACKNOWLEDGEMENTS}

761

762 Amelia Wolf, Sarah Di Vittorio, Dorian Fougeres, Keith M. Slauson, Stacy A. Drury, Brandon M.

763 Collins, William Elliot, Rob Scheller, Alec Kretchun, Mariana Dobre, Erin Brooks, Sam Evans, Tim

764 Holland, Matthew Potts, Adrian Harpold, Sebastian Krogh Navarro. We also thank all the members of

765 the LTW Science Team, LTW Interagency Design Team, LTW Stakeholder Science Committee, and the

766 LTW Stakeholder Committee.

767

768

769

770

771 
Abelson, E.S., K.M. Reynolds, P. Manley, and S. Paplanus. In review. Strategic decision support for conservation management planning in the Lake Tahoe Basin. Forest Ecology and Management.

Angeler, D.H. and C.R. Allen. 2016. Quantifying resilience. Journal of Applied Ecology 53:617624.

Agee, J.K. and C.N. Skinner. 2005. Basic principles of forest fuel reduction treatments. Forest Ecology and Management 211(2):83-96.

Ager, A. A., N. M. Vaillant, and M. A. Finney. 2010. A comparison of landscape fuel treatment strategies to mitigate wildland fire risk in the urban interface and preserve old forest structure. Forest Ecology and Management 259(8):1556-1570.

Ager, A. A., N. M. Vaillant, and A. McMahan. 2013. Restoration of fire in managed forests: a model to prioritize landscapes and analyze tradeoffs. Ecosphere 4(2): art29.

Arkle, R.S., D.S. Pilliod, and J.L. Welty. 2012. Pattern and process of prescribed fires influence effectiveness at reducing wildfire severity in dry coniferous forests. Forest Ecology and Management 276:174-184.

Bagdon, B.A. and C.H. Huang. 2016. Review of economic benefits from fuel reduction treatments in the fire prone forests of the Southwestern United States.

Southwest Fire Science Consortium, Flagstaff, AZ11 pp. https://gallery.mailchimp.com/35f64585b7351c71937d858e9/files/Econ_Final_Web.pdf

Bagdon, B.A., C.H. Huang, and S. Dewhurst. 2016. Managing for ecosystem services in northern Arizona ponderosa pine forests using a novel simulation-to-optimization methodology. Ecological Modelling 324: 11-27.

Bagstad, K.J., D.J. Semmens, S Waage, and R. Winthrop. 2013. A comparative assessment of decision support tools for ecosystem services quantification and valuation. Ecosystem Services 5:27-39. https://doi.org/10.1016/j.ecoser.2013.07.004

Boesch, D.F., P.N. Manley, and T.S. Melis. 2006. The future of water resources adaptive management: Challenges and overcoming them. Water Resources IMPACT 8(3):21-23.

Buckley, M., N. Beck, P. Bowden, M. Miller, B. Hill, C. Luce, W. Elliot, N. Enstice, K. Podolak, and E. Winford. 2014. Mokelumne watershed avoided cost analysis: why Sierra fuel treatments make economic sense. Report, Sierra Nevada Conservancy, Auburn, CA.

California Tahoe Conservancy, editor. 2019. Integrated Vulnerability Assessment of Climate Change in the Lake Tahoe Basin: Technical memos. California Tahoe Conservancy, 1061 Third St, South Lake Tahoe, CA. https://tahoe.ca.gov/wp-content/uploads/sites/257/2020/04/LakeTahoe-Basin-IVA-SET-Tech-Memos.pdf 
Chappell, D. 2009. The workflow way: understanding windows workflow foundation. http://msdn.microsoft.com/en-us/library/dd851337.aspx. Last accessed on 16 April 2021.

Chilton, S.W. 1995. Partnerships for sustainable forest ecosystem management in the Lake

Daily, G, and P.A. Matson. 2008. Ecosystem services: from theory to implementation.

Gordon, S. and K. Reynolds. 2014. The design and use of forest Decision Support Systems in the USA. Pages 460-483 in: Borges, J.G, E.M. Nordstrom, J. Garcia-Gonzalo, T. Hujala, and A. Trasobares (eds.) Computer-based tools for supporting forest management. The experience and the expertise world-wide. Umea, Sweden: Swedish University of Agricultural Sciences. Pages 27-42 in K.N. Johnson, F.J. Swanson, M. Herring, and S. Greene, editors. Bioregional assessments: Science at the crossroads of management and policy. Washington, DC: Island Press.

Gunderson, L.H., Allen, C.R., Holling, C.S., editors. 2010. Foundations of Ecological Resilience; Island Press: London, UK. 
Hessburg, P.F., T.A. Spies, D.A. Perry, C.N. Skinner, A.H. Taylor, P.M. Brown, S.L. Stephens, A.J. Larson, D.J. Churchill, N.A. Povak, P.H. Singleton, B. McComb, W.J. Zielinski, B.M. Collins, R.B. Salter, J.J. Keane, J.F. Franklin, and G. Riegel. 2016. Tamm Review: Management of mixed-severity fire regime forests in Oregon, Washington, and Northern California, Forest Ecology and Management 366:221-250. https://doi.org/10.1016/j.foreco.2016.01.034.

Holling, C.S. 1973. Resilience and Stability of Ecological Systems. Annual Review of Ecology and Systematics 4: 1-23.

Imperial, M. and D. Kauneckis. 2003. Moving from conflict to collaboration: Watershed governance in Lake Tahoe. Natural Resources Journal, 43(4):1009-1055. http://www.jstor.org/stable/24888896

Johnstone, J.F., C.D. Allen, J.F. Franklin, L.E. Frelich, B.J. Harvey, P.E. Higuera, M.C. Mack, R.K. Meentemeyer, M.R. Metz, G.L. Perry, and T. Schoennagel. 2016. Changing disturbance regimes, ecological memory, and forest resilience. Frontiers in Ecology and the Environment 14(7):369-378.

Jones, G. M., R.J. Gutiérrez, D.J. Tempel, S.A. Whitmore, W.J. Berigan, and M.Z. Peery. 2016. Megafires: an emerging threat to old-forest species. Frontiers in Ecology and the Environment 14:300-306. ttps://doi.org/10.1002/fee.1298

Kamenetzky, R. 1982. The relationship between the analytical hierarchy process and the additive value function. Decision Science 13:702-716.

Kim, J.B., E. Monier, B. Sohngen, G.S. Pitts, R. Drapek, J. McFarland, S. Ohrel, and J. Cole. 2017. Assessing climate change impacts, benefits of mitigation, and uncertainties on major global forest regions under multiple socioeconomic and emissions scenarios. Environmental Research Letters 12(4):.045001.

Kolden, C.A. 2019. We're not doing enough prescribed fire in the western United States to mitigate wildfire risk. Fire 2(2):30. https://doi.org/10.3390/fire2020030

Krofcheck, D.J., M.D. Hurteau, R.M. Scheller, and E.L. Loudermilk. 2017. Restoring surface fire stabilizes forest carbon under extreme fire weather in the Sierra Nevada._Ecosphere 8 (1): e01663).

Krogh, S.A., P.D. Broxton, P.N. Manley, and A.A. Harpold. 2020. Using Process Based Snow Modeling and Lidar to Predict the Effects of Forest Thinning on the Northern Sierra Nevada Snowpack. Frontiers in Forests and Global Change 3: 21.

Lake Tahoe Restoration Partnership. 2019. Lake Tahoe West landscape restoration strategy. An interagency report to the Lake Tahoe Restoration Partnership. https://www.nationalforests.org/assets/images/LTW-Landscape-Restoration-Strategy02Dec2019-FINAL.pdf.

Lindström, S. 2000. A contextual overview of human land use and environmental conditions. Pages 23-127 in D.D. Murphy and C.M. Knopp, editors. Lake Tahoe watershed assessment. 
Volume I. U.S. Forest Service General Technical Report PSW-175, Pacific Southwest Research Station, Albany, CA.

Long, J.W., R.W. Goode, and F.K. Lake. 2020. Recentering ecological restoration with tribal perspectives. Fremontia 48(1):

Long, J.W. 2019. Vulnerability assessment of Washoe cultural heritage. Pages 56-61 in California Tahoe Conservancy (eds.), Integrated Vulnerability Assessment of Climate Change in the Lake Tahoe Basin: Technical memos. California Tahoe Conservancy, 1061 Third St, South Lake Tahoe, CA. https://tahoe.ca.gov/wp-content/uploads/sites/257/2020/04/Lake-Tahoe-BasinIVA-SET-Tech-Memos.pdf

Long, J.W.L.N. Quinn-Davidson, and C.N. Skinner. editors. 2014. Science synthesis to support socioecological resilience in the Sierra Nevada and Southern Cascade range. Gen. Tech. Rep. PSW-GTR-247. USDA Forest Service Pacific Southwest Research Station, Albany, CA. 723 p.

Lydersen, J.M., M.P. North, and B.M. Collins. 2014. Severity of an uncharacteristically large wildfire, the Rim Fire, in forests with relatively restored frequent fire regimes. Forest Ecology and Management 328:326-334. https://doi.org/10.1016/j.foreco.2014.06.005

Manley, P.N. 2004. Th future of biodiversity in the Sierra Nevada through the Lake Tahoe basin looking glass. Pages 207-217 in D.D. Murphy and P.A. Stine, editors. Proceedings of the Sierra Nevada Science Symposium. Gen. Tech. Rep. PSW-GTR-193. USDA Forest Service, Pacific Southwest Research Station, Albany, CA.

Maxwell, C.J., J.M. Serra-Diaz, R.M. Scheller, J.R. Thompson. 2020. Co-designed management scenarios shape the responses of seasonally dry forests to changing climate and fire regimes. Journal of Applied Ecology 57(7):1328-1340.

McCaffrey, S., E. Toman, M. Stidham, B. Shindler, S. McCaffrey, E. Toman, M. Stidham, and B. Shindler. 2013. Social science research related to wildfire management: an overview of recent findings and future research needs. International Journal of Wildland Fire 22(1):15-24.)

Mendoza, G.A. and H. Martins. 2006. Multi-criteria decision analysis in natural resource management: A critical review of methods and new modelling paradigms. Forest Ecology And Management 230:1-22.

Miller, B.J. and M.S. Saunders. 2002. The NetWeaver Reference Manual; Pennsylvania State University: College Park, PA, USA.

Miller, B.J.; Saunders, M.S.; Miller, B.J. 2014. NetWeaver. Pages 23-33 in K.M. Reynolds, P.F. Hessburg, and P.S. Bourgeron, editors. Making Transparent Environmental Management Decisions: Applications of the Ecosystem Management Decision Support System. Springer: Berlin, Germany. 
Moghaddas, J.J., B.M. Collins, K. Menning, E.E.Y. Moghaddas, and S.L. Stephens. 2010. Fuel treatment effects on modeled landscape level fire behavior in the northern Sierra Nevada. Canadian Journal of Forest Research 40(9): 1751-1765.

Murphy, P.J. 2014. Criterium DecisionPlus. Pages 35-60 in K.M. Reynolds,., P.F. Hessburg, and P.S. Bourgeron, editors. Making Transparent Environmental Management Decisions: Applications of the Ecosystem Management Decision Support System. Berlin: Springer.

Nair, S. and M. Howlett. 2016. From robustness to resilience: avoiding policy traps in the long term. Sustainability Science 11(6):909-917.

North, M., B.M. Collins, and S.L. Stephens. 2012. Using fire to increase the scale, benefits, and future maintenance of fuels treatments. Journal of Forestry 110:392-401. https://doi.org/10.5849/jof.12-021

Paplanus, S., B. Miller, P. Murphy, K. Reynolds, and M. Saunders. 2014. EMDS 5.0 and Beyond. Chapter 13 in K.M. Reynolds,., P.F. Hessburg, and P.S. Bourgeron, editors. Making Transparent Environmental Management Decisions: Applications of the Ecosystem Management Decision Support System. Berlin: Springer.

Povak, N.A., P.F. Hessburg, C.P. Giardina, R.A. MacKenzie, K.M. Reynolds, C. Heider, E. Salminen, and R.B. Salter. 2017. A watershed decision support tool for managing invasive species on Hawaii Island, USA. Forest Ecology and Management 400: 300-320.

Reynolds, K.M. 2001. Using a logic framework to assess forest ecosystem sustainability. Journal of Forestry 99:26-30.

Reynolds, K.M., and P.F. Hessburg. 2014a. An overview of the Ecosystem Management Decision-Support system. Chapter 1 in Reynolds, K.M., P.F. Hessburg, and P.S. Bourgeron (eds). Making Transparent Environmental Management Decisions: Applications of the Ecosystem Management Decision Support System. Berlin: Springer.

Reynolds, K.M., P.F. Hessburg, and P.S. Bourgeron. 2014b. Synthesis and new directions. Chapter 14 in Reynolds, K.M., P.F. Hessburg, and P.S. Bourgeron (eds). Making Transparent Environmental Management Decisions: Applications of the Ecosystem Management Decision Support System. Berlin: Springer.

Roche, J.W., Q. Ma, J. Rungee, and R.C. Bales. 2020. Evapotranspiration Mapping for Forest Management in California's Sierra Nevada. Frontiers in Forests and Global Change 3(69). https://doi.org/10.3389/ffgc.2020.00069

Ryan, K.C., E.E. Knapp, and J.M. Varner. 2013. Prescribed fire in North American forests and woodlands: history, current practice, and challenges. Frontiers in Ecology and the Environment 11(s1):e15-e24.).

Saaty, T.L. 1994. Fundamentals of Decision Making and Priority Theory with the Analytical Hierarchy Process; RWS Publications: Pittsburgh, PA, USA. 
1000

1001

1002

1003

1004

1005

1006

1007

1008

1009

1010

1011

1012

1013

1014

1015

1016

1017

1018

1019

1020

1021

1022

1023

1024

1025

1026

1027

1028

1029

1030

1031

1032

1033

1034

1035

1036

1037

1038

1039

1040

1041

1042

1043

1044
Safford, H.D., D.A. Schmidt, and C.H. Carlson. 2009. Effects of fuel treatments on fire severity in an area of wildland-urban interface, Angora Fire, Lake Tahoe Basin, California. Forest Ecology and Management 258, 773-787.

Scheller, R., A. Kretchun, T.J. Hawbaker, and P.D. Henne. 2019. A landscape model of variable social-ecological fire regimes. Ecological Modelling 401:85-93.

Scholes, R.J., J. Settele, R. Betts, S. Bunn, P. Leadley, D. Nepstad, and J. Overpeck. 2014. IPCC Working Group II Assessment Report 5 Chapter 4 Terrestrial and Inland Water Systems.

Intergovernmental Panel on Climate Change, Geneva.

Scholl, A.E. and A.H. Taylor. 2010. Fire regimes, forest change, and self-organization in an oldgrowth mixed-conifer forest, Yosemite National Park, USA. Ecological Applications 20(2):362380.

Schoennagel, T., J.K. Balcha, H. Brenkert-Smith, P.E. Dennison, B.J. Harvey, M.A. Krawchuk, N. Mietkiewicz, P. Morgan, M.A. Moritz, R. Rasker, M.G. Turner, and C. Whitlock. 2017. Adapt to more wildfire in western North American forests as climate changes. Proceedings of National Academy of Sciences 114(18):4582-4590.

Seidl, R. 2017. To Model or not to Model, That is no Longer the Question for Ecologists. Ecosystems 20(2):222-228.).

Spies, T.A., J.W. Long, S. Charnley, P.F. Hessburg, B.G. Marcot, G.H. Reeves, D.B. Lesmeister, M.J. Reilly, L.K. Cerveny, P.A. Stine, and M.G. Raphael. 2019. Twenty-five years of the Northwest Forest Plan: what have we learned? Frontiers in Ecology and the Environment 17(9): 511-520.

Stanturf, J.A., B.J. Palik, M.I. Williams, R.K. Dumroese and P. Madsen. 2014. Forest restoration paradigms. Journal of Sustainable Forestry 33(sup1):S161-S194. https://doi.org/10.1080/

Stephens, S.L., J.K. Agee, P.Z. Fule, M.P. North, W.H. Romme, T.W. Swetnam, and M.G. Turner. 2013. Managing forests and fire in changing climates. Science 342:41-42.

Stephens, S.L., N. Burrows, A. Buyantuyev, R.W. Gray, R.E., Keane, R. Kubian, S. Liu, F. Seijo, L. Shu, K.G. Tolhurst, and J.W. van Wagtendonk. 2014. Temperate and boreal forest megafires: characteristics and challenges. Frontiers in Ecology and the Environment 12:115122. https://doi.org/10.1890/120332

Stevens, J.T., B.M. Collins, J.W. Long, M.P. North, S.J. Prichard, L.W. Tarnay, and A.M. White. 2016. Evaluating potential trade-offs among fuel treatment strategies in mixed-conifer forests of the Sierra Nevada. Ecosphere.7(9): e01445-n/a.

Swanson, F.J., and S. Greene. 1999. Perspectives on scientists and science in bioregional assessments. Pages 55-70 in K.N. Johnson, F.J. Swanson,,M. Herring, and S. Greene, editors Bioregional assessments: Science at the crossroads of management 
1045 and policy. Washington, DC: Island Press.

1046

1047

1048

1049

1050

1051

1052

1053

1054

1055

1056

1057

1058

1059

1060

1061

1062

1063

1064

1065

1066

1067

1068
Urgenson, L.S., C.M. Ryan, C.B. Halpern, J.D. Bakker, R.T. Belote, J.F. Franklin, R.D. Haugo, C.R. Nelson, and A.E. Waltz. 2017. Visions of restoration in fire-adapted forest landscapes: lessons from the Collaborative Forest Landscape Restoration Program. Environmental Management 59(2):338-353.

Vacik, H., C. Torresan, T. Hujala, C. Khadka, and K. Reynolds. 2013. The role of knowledge management tools in supporting sustainable forest management. Forest Systems 22:442-455

Walker, B.; Holling, C.S.; Carpenter, S.R.; Kinzig, A.P. Resilience, Adaptability and Transformability in Social-ecological Systems. Ecol. Soc. 2004, 9, 5.

Walker, B.H., D. Salt. 2010. Resilience Practice: Building Capacity to Absorb Disturbance and Maintain; Island Press: Washington, DC, USA,

Walters, J.R. and N.R. Nielsen. 1988. Crafting Knowledge-based Systems. Wiley, New York.

Weible, C., P. Sabatier, and M. Nechodom. 2005. No sparks fly: policy participants agree on thinning trees in the Lake Tahoe basin. Journal of Forestry 103(1):5-9.

https://doi.org/10.1093/jof/103.1.5

Williams, B.K. 2011. Adaptive management of natural resources-framework and issues.

Journal of environmental management, 92(5):1346-1353. 


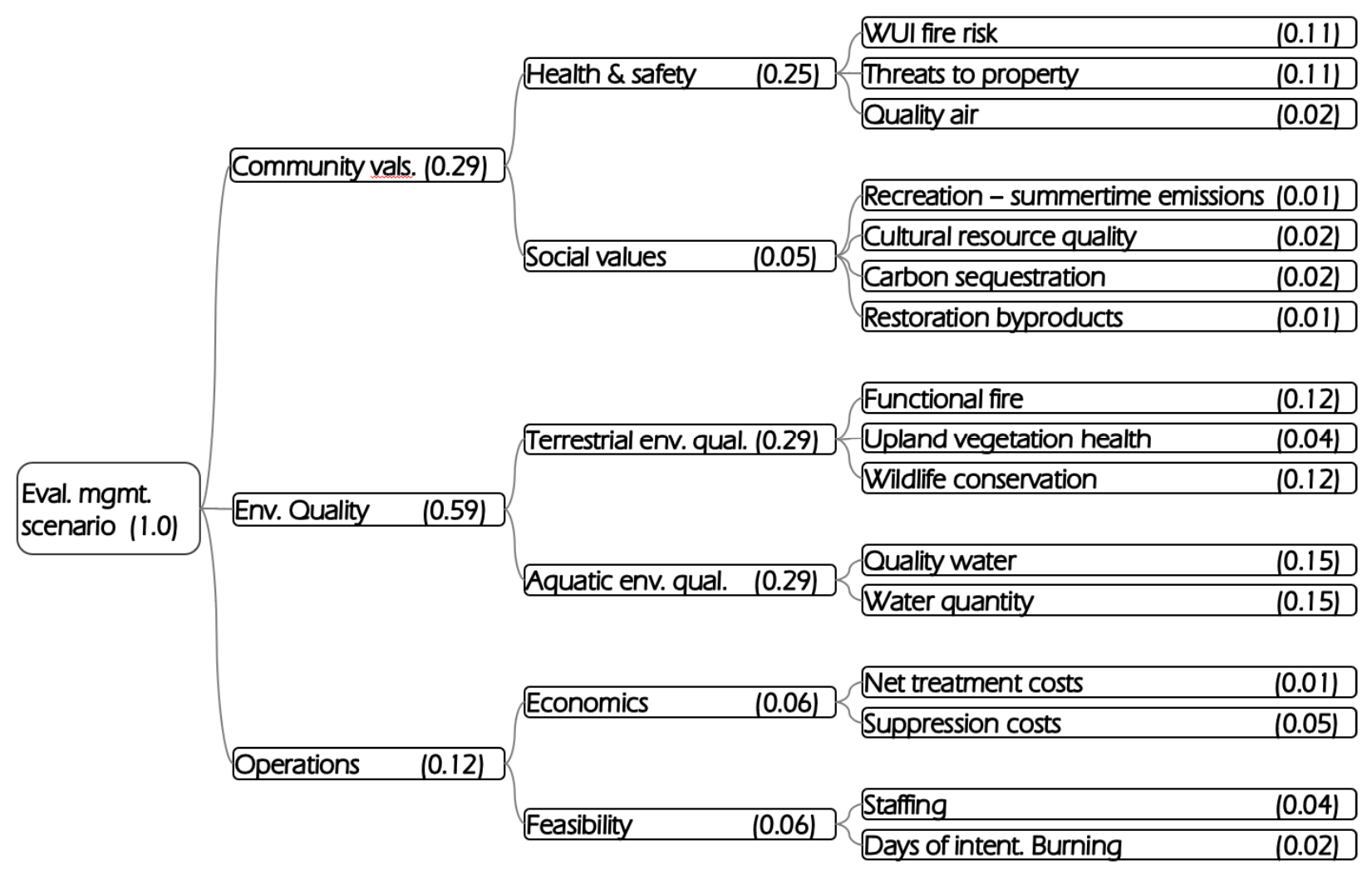

Figure 1. Decision model hierarchy to address the performance of management scenarios in achieving desired conditions across three focal areas: environmental quality, community values, and management operations. Each focal area is represented by two topic areas and each topic is represented by two to four attributes, for a total of 16 attributes. Parenthetical values indicate weighting derived by stakeholders (rounded to two decimals for display purposes), with assigned weights summing to one for each tier of the hierarchy. 


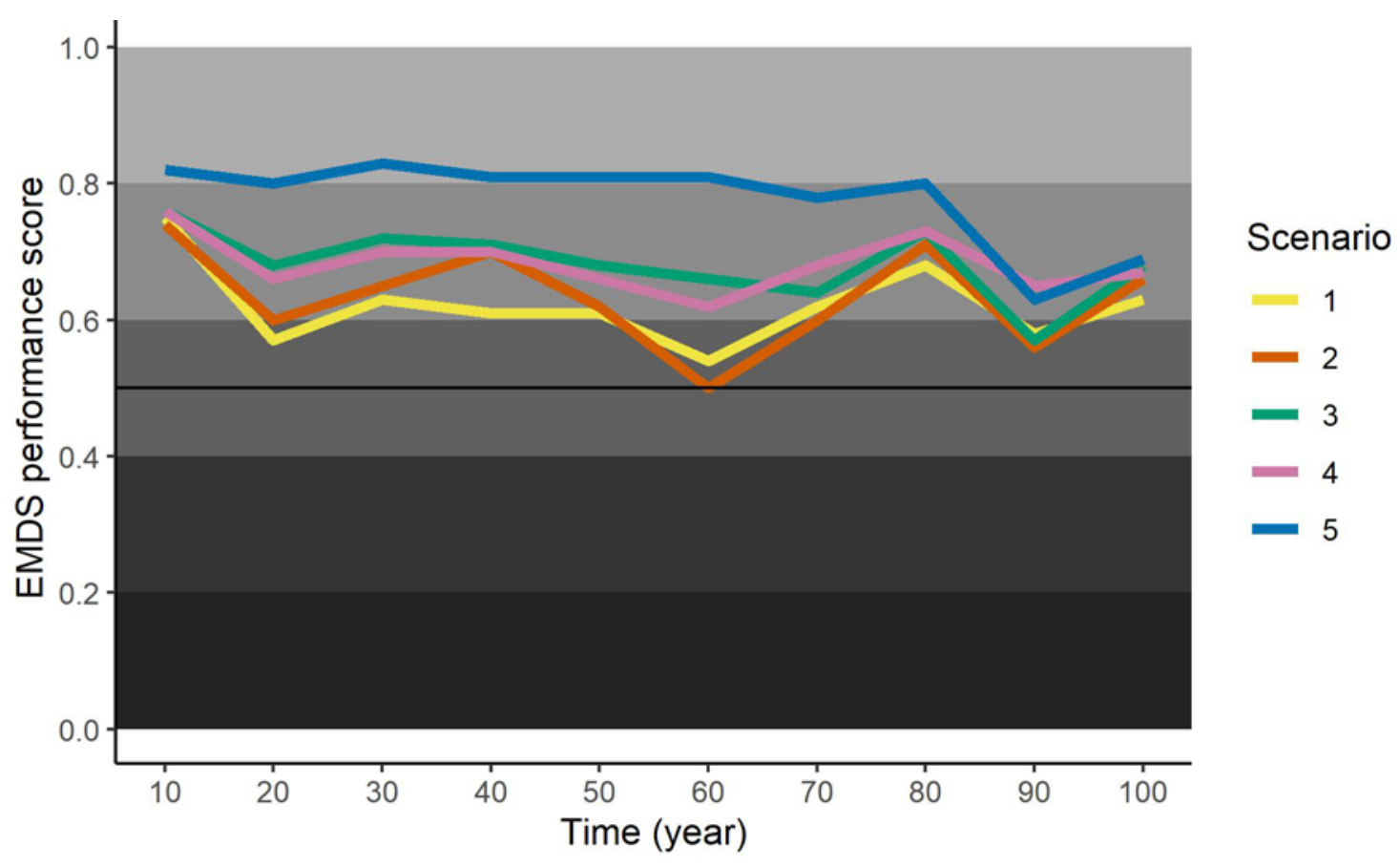

1080 Figure 2. Performance of five management scenarios (S1-S5) in terms of meeting overall desired 1081 conditions over a 100-year time period (2010-2110) on the west side of the Lake Tahoe basin. 1082 Scenarios are arrayed from minimal management investment (S1) to landscape-wide 1083 management using thinning (S3) or fire (S4 and S5). Forest conditions resulting from each of 1084 management scenarios were modeled using LANDIS-II and evaluated each decade across an 1085 array of metrics representing environmental quality, community values, and management 1086 operations using the Ecosystem Management Decision Support tool (EMDS). Scenarios with 1087 performance scores closer to one indicate that optimal conditions resulted from management, 1088 while performance scores near zero that indicate poor conditions resulted. 


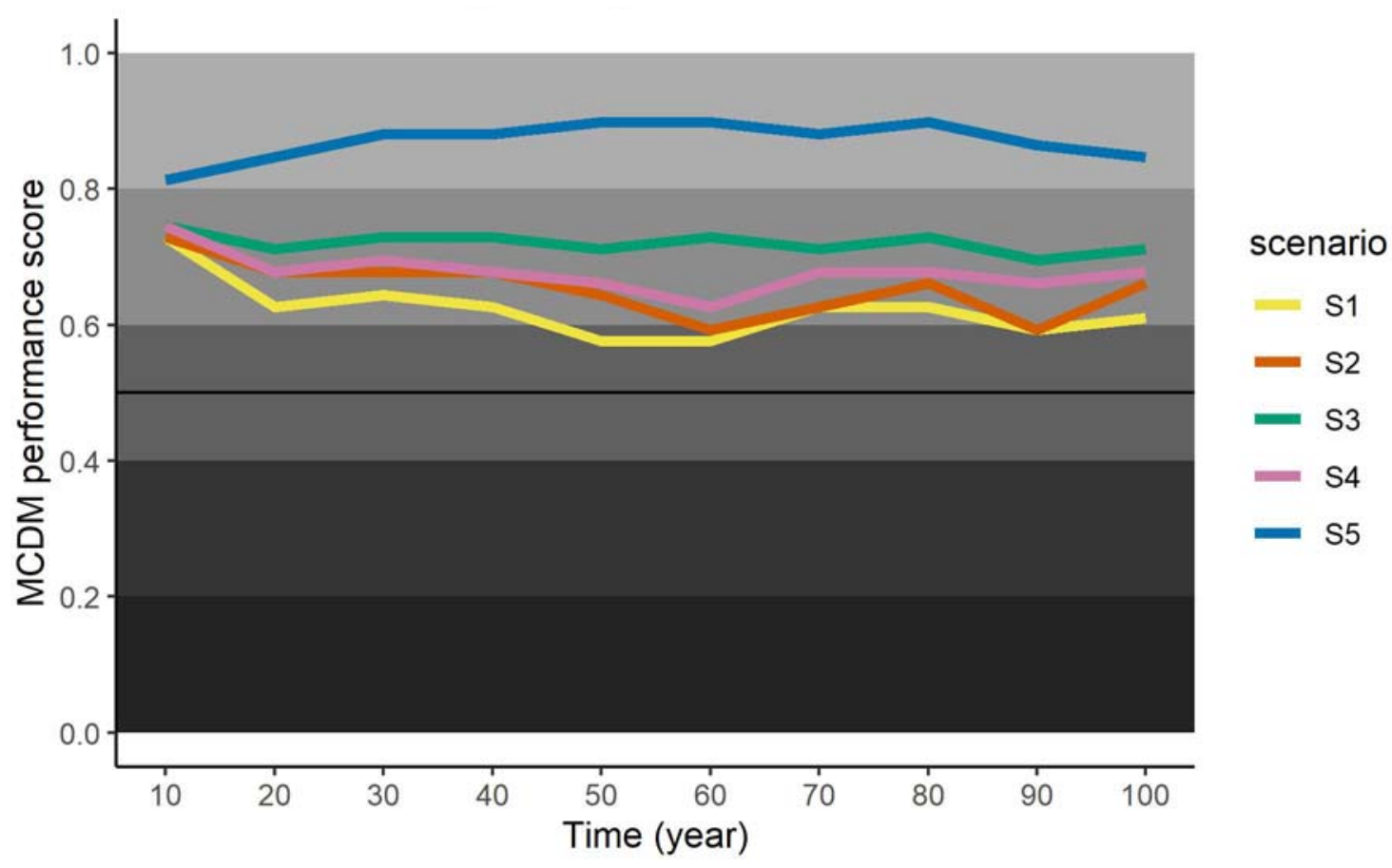

1090 Figure 3. Performance of five management scenarios (S1-S5) in terms of meeting desired 1091 environmental quality outcomes over a 100-year time period (2010-2110) on the west side of the 1092 Lake Tahoe basin. Scenarios are arrayed from minimal management investment (S1) to 1093 landscape-wide management using thinning (S3) or fire (S4 and S5). Forest conditions resulting 1094 from each of management scenarios were modeled using LANDIS-II and evaluated each decade 1095 across an array of metrics representing environmental quality, community values, and 1096 management operations using the Ecosystem Management Decision Support tool (EMDS). 1097 Scenarios with performance scores closer to one indicate that optimal conditions resulted from 1098 management, while performance scores near zero that indicate poor conditions resulted. 


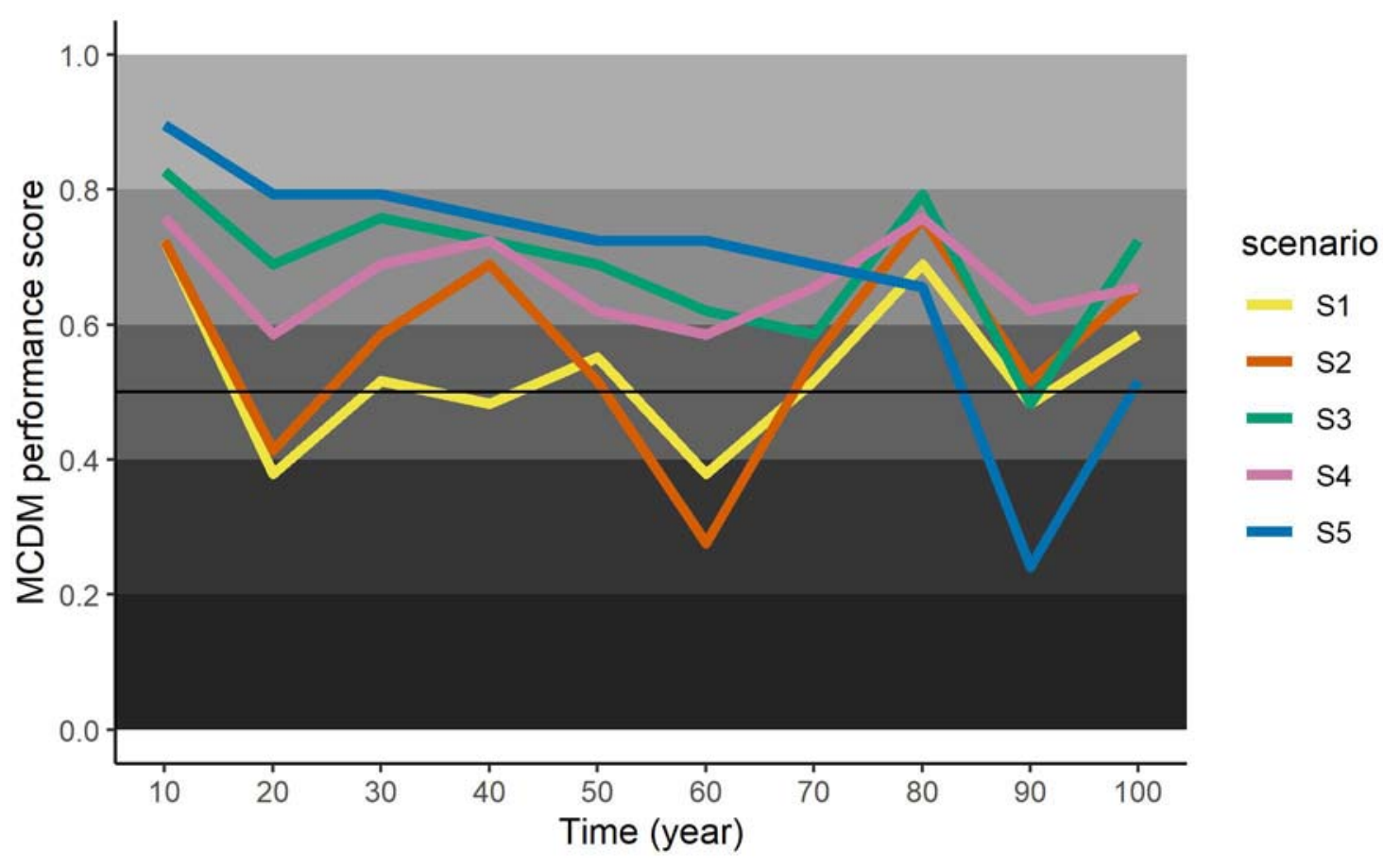

1101 Figure 4. Performance of five management scenarios (S1-S5) in terms of meeting desired 1102 community values outcomes over a 100-year time period (2010-2110) on the west side of the

1103 Lake Tahoe basin. Scenarios are arrayed from minimal management investment (S1) to

1104 landscape-wide management using thinning (S3) or fire (S4 and S5). Forest conditions resulting

1105 from each of management scenarios were modeled using LANDIS-II and evaluated each decade 1106 across an array of metrics representing environmental quality, community values, and 1107 management operations using the Ecosystem Management Decision Support tool (EMDS).

1108 Scenarios with performance scores closer to one indicate that optimal conditions resulted from 1109 management, while performance scores near zero that indicate poor conditions resulted. 


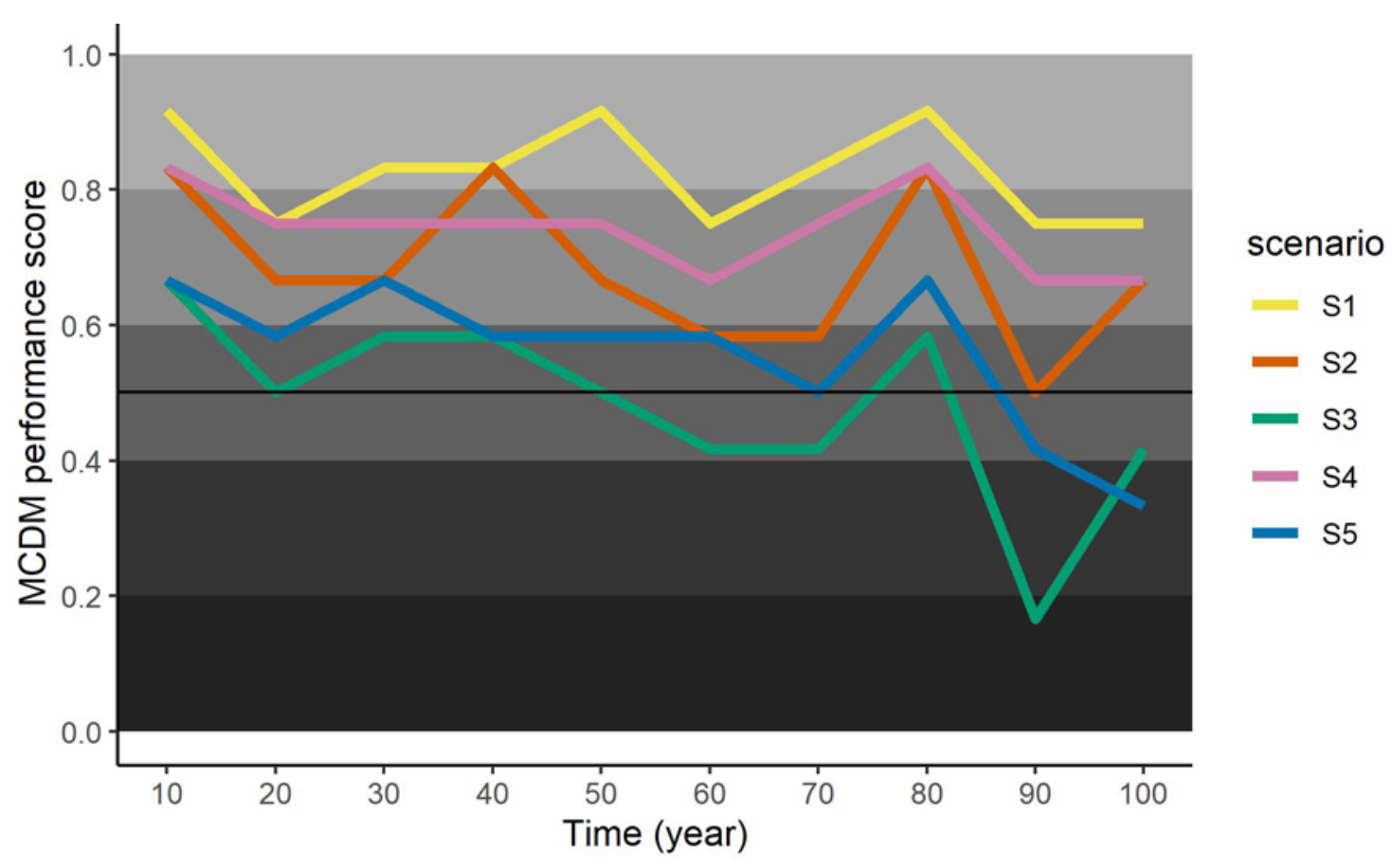

1116 Figure 5. Performance of five management scenarios (S1-S5) in terms of meeting desired 1117 management operations outcomes over a 100-year time period (2010-2110) on the west side of 1118 the Lake Tahoe basin. Scenarios are arrayed from minimal management investment (S1) to 1119 landscape-wide management using thinning (S3) or fire (S4 and S5). Forest conditions resulting 1120 from each of management scenarios were modeled using LANDIS-II and evaluated each decade 1121 across an array of metrics representing environmental quality, community values, and 1122 management operations using the Ecosystem Management Decision Support tool (EMDS).

1123 Scenarios with performance scores closer to one indicate that optimal conditions resulted from 1124 management, while performance scores near zero that indicate poor conditions resulted. 


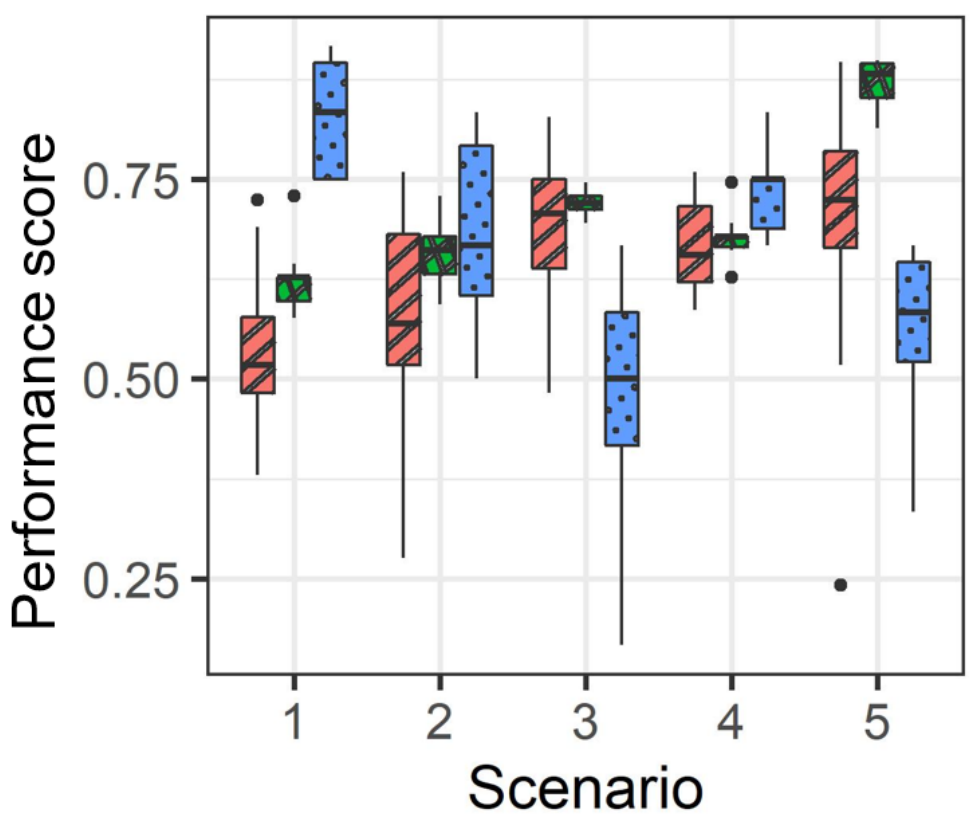

\section{Focal area}

Community values

Environmental quality

Operations

1127 Figure 6. Comparison of the performance of five management scenarios in meeting objectives for three focal areas (environmental quality, community values, and management operations) based on a multi-criterion decision model with 16 attributes for conditions across the west side of the Lake Tahoe basin. 


\section{TABLE LEGENDS \& TABLE}

1132 Table 1. Management scenarios evaluated using Ecosystem Management Decision Support tool 1133 for the Lake Tahoe West restoration landscape.

\begin{tabular}{|c|c|c|}
\hline $\begin{array}{l}\text { Scenario } \\
\text { number }\end{array}$ & Description & Management specifications \\
\hline 1 & Fire suppression only & $\begin{array}{l}\text { The only management activity was to suppress } \\
\text { fires that start naturally. No other management } \\
\text { activities were implemented in this scenario. }\end{array}$ \\
\hline 2 & $\begin{array}{l}\text { Wildland-urban interface } \\
\text { focus }\end{array}$ & $\begin{array}{l}\text { Management activities were focused } \\
\text { predominantly on forest thinning in the wildland- } \\
\text { urban interface (WUI, areas near human } \\
\text { habitation). This management strategy was } \\
\text { designed to provide a buffer of defensible space } \\
\text { around human-built structures and property, with } \\
\text { the goal of protecting those properties and their } \\
\text { inhabitants. It treated approximately } 1.8 \% \text { of the } \\
\text { vegetated area each year, all in the WUI (58\% of } \\
\text { the landscape). This scenario most closely } \\
\text { resembled current management activities in the } \\
\text { Lake Tahoe basin. }\end{array}$ \\
\hline 3 & Thinning-based approach & $\begin{array}{l}\text { This scenario builds upon Scenario } 2 \text { by } \\
\text { expanding management activities into the } \\
\text { remaining forested landscape ( } 42 \% \text { of the } \\
\text { landscape) in proximity to the WUI and used } \\
\text { predominantly mechanical and some hand } \\
\text { removal methods to thin the forest and reduce } \\
\text { woody biomass. It treats approximately } 6.7 \% \text { of } \\
\text { the vegetated area each year. }\end{array}$ \\
\hline 4 & Fire-based approach & $\begin{array}{l}\text { This scenario builds upon Scenario } 2 \text { by } \\
\text { expanding management activities into the } \\
\text { remaining forested landscape. While Scenario } 3 \\
\text { employs mechanical and hand methods to thin the } \\
\text { forest, Scenario } 4 \text { uses primarily prescribed fire } \\
\text { and managed wildfire. This scenario treats } \\
\text { approximately } 4 \% \text { of the vegetated area each } \\
\text { year. }\end{array}$ \\
\hline 5 & $\begin{array}{l}\text { Extensive fire-based } \\
\text { approach }\end{array}$ & $\begin{array}{l}\text { This scenario builds upon Scenario } 2 \text { by } \\
\text { expanding management activities into the } \\
\text { remaining forested landscape. Like Scenario } 4 \text {, } \\
\text { Scenario } 5 \text { predominately employs fire-driven } \\
\text { techniques, but with a greatly expanded the use of } \\
\text { prescribed fire. This scenario treats a } \\
\text { approximately } 7.2 \% \text { of the vegetated area each } \\
\text { year, slightly more than Scenario } 3 \text {, but with the } \\
\text { majority of treatments }(75 \%) \text { being fire. }\end{array}$ \\
\hline
\end{tabular}


1134 Table 2. Attributes of the three focal areas evaluated using the Ecosystem Management Decision

1135 Support tool to determine the degree to which five different management scenarios met desired 1136 conditions for the Lake Tahoe West landscape.

\begin{tabular}{|c|c|}
\hline $\begin{array}{c}\text { Attributes of } \\
\text { focal areas }\end{array}$ & Modeling category description \\
\hline \multicolumn{2}{|l|}{ Environmental quality: } \\
\hline Functional fire & $\begin{array}{l}\text { Measures how close to the natural range of variability fires are predicted to burn at } \\
\text { low, moderate, and high severity. }\end{array}$ \\
\hline Upland vegetation health & $\begin{array}{l}\text { Considers to what extent early, mid, and late seral forests are represented across the } \\
\text { landscape compared to modern reference conditions. }\end{array}$ \\
\hline Wildlife conservation & $\begin{array}{l}\text { Represents species richness, biodiversity across multiple functional groups, and the } \\
\text { quality and connectivity of old-growth associated species habitat. }\end{array}$ \\
\hline Quality water & $\begin{array}{l}\text { Represents fine sediment and nutrient loading to streams and lakes compared to } \\
\text { baseline conditions. }\end{array}$ \\
\hline Water quantity and timing & $\begin{array}{l}\text { A qualitative measure of increased water yield and delayed runoff to down-stream } \\
\text { water bodies and meadows. }\end{array}$ \\
\hline \multicolumn{2}{|l|}{ Community values: } \\
\hline Fire risk to property & Measured by the value of properties threatened by predicted wildfires. \\
\hline $\begin{array}{l}\text { Wildland-urban interface } \\
\text { fire risk }\end{array}$ & The percent of forest in areas, near communities, at risk of burning at high severity. \\
\hline Quality air & $\begin{array}{l}\text { Represented using a proxy based upon the number of predicted high, very high, and } \\
\text { extreme emission days. }\end{array}$ \\
\hline Carbon sequestration & $\begin{array}{l}\text { Represents emissions with global warming implications including carbon stored in } \\
\text { the entire system (in-forest and harvested wood products). }\end{array}$ \\
\hline Restoration byproduct & $\begin{array}{l}\text { Indicates the predicted amount of biomass and wood product utilization resulting } \\
\text { from a management scenario. }\end{array}$ \\
\hline Cultural resource quality & $\begin{array}{l}\text { Evaluated through a synthesis of indicators important to the Washoe Tribe, } \\
\text { including predicted amounts of low-intensity fire, habitat for culturally important } \\
\text { terrestrial species (e.g., deer, flicker, mountain quail, and aspen), and beneficial } \\
\text { water flows to meadows and water bodies. }\end{array}$ \\
\hline Recreation quality & Measured by summer-time smoke impact and winter-time snowpack duration. \\
\hline \multicolumn{2}{|l|}{ Management operations: } \\
\hline Net treatment cost & $\begin{array}{l}\text { Consists of cost of treatments (thinning and prescribed burning) less value of } \\
\text { products removed. }\end{array}$ \\
\hline Suppression cost & All cost related to suppressing wildland fires. \\
\hline Staffing & $\begin{array}{l}\text { Represents the number of agency personnel required to implement forest } \\
\text { management projects. }\end{array}$ \\
\hline $\begin{array}{l}\text { Days of intentional } \\
\text { burning }\end{array}$ & The number of days of prescribed fire or pile burning. \\
\hline
\end{tabular}


1139 Table 3. Decision model outputs (range from 0 to 1) interpreted in terms of performance scores 1140 and associated condition classes in the evaluation of management scenarios in the Lake Tahoe 1141 West landscape restoration project.

\begin{tabular}{|l|l|}
\hline Performance score & Condition class \\
\hline $0.8-1.0$ & Optimal \\
\hline $0.6-0.8$ & Good \\
\hline $0.4-0.6$ & Marginal \\
\hline $0.2-0.4$ & Suboptimal \\
\hline $0.0-0.2$ & Poor \\
\hline
\end{tabular}

1142

1143 
1144 Table 4. Summary of sensitivity analyses calculated by Criterium DecisionPlus (CDP) for each 1145 of the 10 decadal time steps of the 100 -year period modeled.

\begin{tabular}{|c|c|c|c|c|c|}
\hline \multirow[b]{2}{*}{ Time step ${ }^{a}$} & \multirow{2}{*}{$\begin{array}{l}\text { Top rated } \\
\text { scenario }\end{array}$} & \multicolumn{2}{|c|}{$\begin{array}{l}\text { Most sensitive } \\
\text { focal }\end{array}$} & \multirow[b]{2}{*}{ Criticality $^{c}$} & \multirow{2}{*}{$\begin{array}{l}\text { Usurping } \\
\text { scenario }\end{array}$} \\
\hline & & area & Weight $^{\mathbf{b}}$ & & \\
\hline & & & & & \\
\hline \multirow[t]{2}{*}{10} & 5 & ns & 0.12 & 16.78 & 1 \\
\hline & & & & & \\
\hline \multirow[t]{2}{*}{20} & 5 & ns & 0.12 & 40.62 & 4 \\
\hline & & & & & \\
\hline \multirow[t]{2}{*}{30} & 5 & ns & 0.12 & 40.26 & 1 \\
\hline & & & & & \\
\hline \multirow[t]{2}{*}{40} & 5 & ns & 0.12 & 26.89 & 2 \\
\hline & & & & & \\
\hline \multirow[t]{2}{*}{50} & 5 & ns & 0.12 & 32.83 & 1 \\
\hline & & & & & \\
\hline \multirow[t]{2}{*}{60} & 5 & ns & 0.12 & 50.25 & 1 \\
\hline & & & & & \\
\hline \multirow[t]{2}{*}{70} & 5 & ns & 0.12 & 27.47 & 4 \\
\hline & & $\mathrm{Er}$ & & & \\
\hline \multirow[t]{2}{*}{80} & 5 & quality & 0.59 & 21.28 & 4 \\
\hline & & Er & & & \\
\hline \multirow[t]{2}{*}{90} & 4 & quality & 0.59 & 1.15 & 5 \\
\hline & & & & & \\
\hline 100 & 5 & ns & 0.12 & 1.21 & 4 \\
\hline
\end{tabular}

$1146{ }^{\mathrm{a}}$ The CDP model was run at each time step, comparing performance of the five scenarios at each 1147 step.

$1148 \quad{ }^{\mathrm{b}}$ Weight of the most sensitive criterion in the decision model.

$1149{ }^{\mathrm{c}}$ Criticality is the absolute percent change in weight on the most sensitive focal area in the decision 1150 model that would cause the top rated scenario to be replaced by an alternative (usurping) scenario. 


\section{Supplemental information:}

1153 Appendix 1: CriterionDecision Plus (CDP) model in CDPX format.

1154

Appendix 5: Raw data inputs for the NetWeaver model (i.e. appendix 2) and CriterionDecison Plus (i.e. appendix 1)

Appendix 6: Multi-criteria decision model values and summary statistics for focal areas, topic areas, and attributes. 